\title{
KLAXON EM MARSELHA
}

\section{Marla Allce de Oliveira Faria *}

A questão da projeção internacional de Klaxon ainda está por ser inteiramente esclarecida. Segundo podemos ler na introduçāo de Mário da Silva Brito à reedição da revista (1972), Menotti del Picchia foi talvez o primeiro que divulgou a idéia da "forte repercussão além fronteiras". E mais adiante: "Rompendo as fronteiras nacionais, foi bater nas portas da França, da Itália e de Portugal". 1 Mário da Silva Brito endossa essas afirmações de primeira hora quando escreve na sua Introdução: "Klaxon teve realmente projeção internacional". 2 Outros críticos. como Afrânio Coutinho na Literatura no Brasil, já vinham repetindo a mesma afirmação.

No que diz respeito às relações de Klaxon com a França, pudemos recentemente, em pesquisa na Biblioteca Nacional de Paris, complementar o trabalho de Cecllia de Lara, que estudou o relacionamento de Klaxon com os simbolistas belgas da revista Lumière: Roger Avermaëte. Marcel Millet, Henri Mugnier.

$\mathrm{Na}$ realidade, a projeção de Klaxon na França, até que surjam documentos em contrário, parece que se deu entre um pequeno grupo de província, que editava a revista La Criée, em Marselha. Esta revista foi citada diversas vezes em Klaxon. No número 4, nos seguintes termos: "Boa revista, com colaboraçāo escolhida. Entre outros nomes: Han Ryner, Léon Franc, Marcel Millet, Paul Myrriam - Convém citar "Bain", de Marcel Millet e "Propos sur le quai", de Lén

* Maria Alice Faria é Doutor pela Universidade de São Paulo (1970) com a tese Astarte a a Espiral, um confronto entre Alvareg de Azevedo e Alfred de Musget que recebeu o premio Gavernador do Estado de \$ao Paulo a fol publicado peln Comissão Estadual de Literatura em 1973 (368 p.). Tres anos antes fá havia publicado, também pela Comissko Estadual de Literatura Brasllelros no Instituto Historico de Parls (104 p.). Desde 1966 colabora em várias revistas especializadas e no Suplemento Literário do Eatado do Sko Panjo. Atualmente, leciona, na condicho de Professor Títular, Lingua e Literatura Francesa na Faculdade de Filosofia de Marfia. Bto Paulo,

1 Klaxon, Såo Paulo, nova ed., 1972.

2 Ibjd.. 
Franc". 3 No número 5, a referência é menor: "Número de julho, com interessante colaboração de Marcel Millet, Léon Franc, etc." 4 No número scguinte, à página 14: "La Criée. número de agosto da interessante revista marselhesa. A destacar, como sempre, as colaboraçōes de Marcel Millet. Léon Franc, etc." 5 No número 7, uma simples mençāo, para "Muito agradável a leitura do número de outubro da revista marselhesa", 6 para desaparecer $\mathrm{cm}$ seguida qualquer menção ao úlimo número de Klaxon. E publica também um pequeno conto ou crônica de Marcel Millet. principal colaborador de La Criée.

A revista La Criée, por sua vez, tendo recebido números de Klaxon. faz mençāo a ela no "memento" da revista das revistas. Inicialmente, como "Klaxon du Brèsil" ( . $^{\circ} 14$ ), e "Klaxon, revue brésilienne" (n." 15). Por fim, no número 18 (novembro de 1922), publica um artigo de Serrgio Milliet sobre Henri Mugnier, que conheceu pessoalmente na Suiça, (artigo datado de Sāo Paulo. de 8-7-1922), comenta o teor geral da revista e estampa ainda a tradução do poema " $O$ discóbolo", de Guilherme de Almeida. A referência, na integra. é a seguinte:

Klaxon (Sāo Paulo, rue Dircita, 23), revue brësilienne et française. Du numciro de juillet, signalons un remarquable poème de $M$. Guilherme de Almeida, dont voici une traduction libre:

Dans la poussière olympique du cirque

Sous un soleil violent, ils lançaint le disque

qui filait haut et vibrait loin

comme un soleil de bronze.

Leurs gestes

étaient assurés

et leurs pieds marqués sur l'arene mobile.

Et le petit astre de cuivre, rapide,

fuyait de leurs bras tendus

et lustrés d'huiles,

telle, de l'arc puissant - une flèche.

Tous les yeux

le suivaient dans la brève trajectoire aérienne

et se fixaient

au feu métallique du petit soleil.

Et ils ne voyaient pas même l'autre - le vrai:

inaccessible et paraîssant moindre. 7

Ora, a que era a revista La Criee, de Marselha, e o que poderia representar no panorama Jiterário da França e de sua vanguarda?

Trata-se de uma pequena revista provinciana, de produçāo desi-

3 Kinxon, Siro Paulo, (4): 16, ago. 1929.

4 Klaxod, Săo Pilulo. (5): 13, set. 1922.

5 Klaxon, Săo Paulo, (6): 14, out. 1922.

6 Kluxan, São Paulo, (T): 16. nov. 1922.

T In Crié, Marsellle, (18): 15. 1922. 
gual, onde um Jean Giono ainda desconhecido e um Antonin Artaud colaboram ao lado da mais lamentável produção feminina.

A Biblioteca Nacional de Paris possui uma coleção incompleta, a partir do n. ${ }^{\circ}$, de janeiro de 1922 . Supöe-sc, então, que a revista tenha sido fundada em 1921, ou mesmo antes. Até o n. ${ }^{\circ} 27$, ela se apresenta no seu formato maior; daí até o final, o tamanho fica reduzido e a revista parece extinguir-sc $\mathrm{cm}$ fevereiro de 1923, com dois números juntos, sinal, geralmente, de publicaçāo agonizante...

E uma brochura com 16 páginas. A capa branca, num papel idêntico ao dos textos, apresenta $\mathrm{cm}$ todos os números uma xilogravura representando um homem nu, musculoso, gritando c com um braço erguido em atitude de protesto. Ele cstá montado num cavalo com as patas dianteiras levantadas. No seu todo, trata-se de um meio caminho entre a novidade e o tradicional.

A posição literária de La Criée fica num vago modernismo que, aliás, as colaborações desmentem. A revista n. 8 publica uma folha. volante, a propósito da fundação da "Société de la Criée", uma súmula do que pretende ser a revista:

La Crlée fait appel à tous les sincères, ì tous les désintéressés de l'art et des lettres. Point de chefs! des collaborateurs. des associćs. Toutes les philosophies, toutes les opinions, toutes les hardiesses! De la vie!

Modeste, La Criée veut, dans notre rayonnante Marseille, apporter sa contribution à la recherche des significations des mouvements de l'esprit moderne.

Na realidade, a revista não apresenta colaboraçāo ousada, não indo além de um cpigonismo simbolista, com alguns toques futuristas. Marcel Brion assegura os estudos literários, apresentando Apollinaire, Cendrars, que sāo os mais modernos apregoados por ela. A revista resenha publicação do momento como L'Esprit Nouveau. Mas a colaboração do diretor da revista, Léon Franc, tāo louvado em Klaxon, não uit rapassa versos aflitivamente rimadinhos e ritmados tradicionalmente, de atmosfera decadente; e sua prosa não tem características especiais. Dos versos abaixo, por exemplo, temos uma idéia das possibilidades poéticas do diretor da revista:

\section{Le Yachet pavoisé}

La vague est un vin mousseux, Sur la strade qui m'allonge Au dimanche paresseux Gonflé de joie et de songe. 8

etc.

Da mesma forma, outros poemas rimados ou em versos livres mantém a mesma atmosfera melancólica, cinzenta da poesia decadente. Eis, por exemplo, o início de "Lunaire" de Yves Blanc:

8 I a Criée, Margeille, (8), jan. 1922. 
La dune se déploie ainsi qu'un promontoire

Entre la mer mouvante et le vicux chemin creux.

La lune aux flots se joue, et l'argente, et le moire,

Et l'horizon s'accrit jusqu'au velours des cieux. ${ }^{9}$

E no n. 19 de dezembro de 1922:

Je revois, je revois ce décor adorable,

Cette fin de beau jour de l'automne passé,

Dont la douceur fondait le ciel, la mer, le sable

Et nous enveloppait d'un bonheur nacré.

etc.

Do mesmo tcor são os poemas de Gasparone, "Euphorie", no n." 12. de maio de 1922, evocando Mallarmé:

Les collines oú la brume

Fume,

Les clartés dont la houle

croule

Au ciel rose, hyacinthe et mauve

S'éveillant à l'aube vierge.

o moment, doux, primitif, éternel,

Oú sur le frisson des prés.

Le matin ous tord ses voiles

Trempés!

En l'air léger il neige des promesses.

Et soudain

D'un déluge de feu l'irradiement immense

Un poème Mallarméen...

e sobretudo este "Soir de provence" de Jean Karon:

La nuit tombe, lasse.

Une immense lune, rouge comme un soir de cuivre neuf, émerge de quelque part.

La plaine descend vers le Rhöne. 10

etc.

Marcel Millet, provavelmentc o elemento de ligaçāo entre brasileiros e franceses. escreve bastante na revista $\mathrm{c}$ os seus poemas sāo do mesmo teor, mas em versos brancos. como "L'Ami", estampado com uma epigrafe de Verlaine:

La solitude bonne au travail; mais des soirs

il n'y a plus d'huile dans la lampe,

Psyché n'est qu'une humble servante,

ayez pitié de cette pauvre femme...

9 1. Criée, Marseille, (14). juil. 1922.

10 L. Criée, Marseille, (13), jin 1922. 
Des soirs cinglés de vent d'automne, Des doutes, et l'angoisse monotone.

Savoir tellement qu'il ne passera personne.

Le lendemain est déjà venu On ouvre la porte.

Soleil pâle, odeur de la mer, un matin vivant et qu'on voudrait clair comme un joli rayon d'enfance.

(O novo amigo chega. cumprimentos gague,jados, ambos trocam idéias sobrc os mesmos livros que apreciam).

J'irai te voir dans ton logis sur la colline.

J'irai. Prends ce Verlaine, et Vildrac $\delta$ l'ami!

Tu reviendras souvent dans cette maison sage

Toute petite, fervente et calme?

Et hier, disais-je, hier, j'ai douté de moi-même et des autres...

Je ne sais plus, je ris, mes mains sur tes épaules

et que nous nous regardions en face! 11

Mesmo Antolin Artaud não escapa a estas deliquescências e langores. Além de algumas crônicas teatrais, publicará um soneto, "Navire mystique" 12 e versos brancos, como em "Saint François d'Assissi" 13

Assim, o poema "Bain", de Marcel Millet, citado em Klaxon, representa realmente uma das "ousadias" preconizadas pelo n." 8 da revista. Trata-se da descrição das sensaçōes físicas causadas por um banho de mar: euforia do corpo em contacto com os elementos são exaltados. $O$ todo se enquadra nas tendências futuristas de cantar a força física, o corpo nu e livre c o estilo está adequado ao tema.

Mərcel Millet publica também diversos contos, novelas, como "Sixte Boufardel" 14 (na íntegra em diversos números) e um capítulo de um romance intitulado Jacques, le Paresseux, 15 recém-editado pela Librairie de France, Paris. Mas seu estilo não tem nada de especial que mereça ser relevado. Aliás. na prosa, apenas Jean Giono, ainda totalmente desconhecido, revela um estilo pessoal e já acabado.

Finalmente, para se ter uma idéia da colaboração feminina, ao

11 La Criḱe, Margellle, (9): 3, fev. 1922.

12 Ia Criée, Marsellle, (14), Jull. 1923.

13 Is Crićo, Marselle, (18), nov. 1922.

14 La Crice, Marsellle, (14/17), 1822.

15 La Crlée, Marsellle, (17), oct. 1922. 
Iado das afetaçōes de Cécile Guyon, que enaltece a crônica familiar, basta um exemplo de Magde Millet (uma parente de Marcel?) para nos dar uma idéia do nivel das colaboraçōes:

\section{Trop Ioin}

Devant le brasier de lumiere que dévore Paris tous les soirs, J'ai rêvé à toi $\hat{o}$ "notre Aimé!"

J'ai vu le paisible jardin

tout blanc des caresses de la lune

la petite maison et la chambre tiède, ton berceau, ton sommeil d'ange,

la broussaille, d'or sur l'oreiller, ton poing mignon soutenant ta joue rose

et ta main... ta menotte aux fossettes rondes.

ces cinq "nids d'amour" comme je voudrais les embrasser

[ce soir!

Mais tu es loin, trop loin,

Et mon coeur sanglote,

Tandis que mes levres sourient à ta chère Image... 16

Tratava-se em suma de uma pequena revista de província, acolhendo todos os amigos e parentes, indiscriminadamente, e onde a vanguarda nāo havia chegado, em realidade. Ficavam eles ainda no néo-simbolismo de antes da guerra, vagamente estimulados pelas tendências do grupo de Esprit Nouveau, e o exemplo mais avançado de modernismo, como o citado "Bain". de Marcel Millet, não ultrapassava os modismos do manifesto futurista.

Nāo se pode pois dizer que a revista Klaxon tenha se divulgado num meio vanguardista, na França. $E$ nem mesmo representativo literariamentc. Por outro lado, conclui-se que, pelos comentários favoráveis de Klaxon a La Críe, e pelo entusiasmo demonstrado por esta para com o poema de Guilherme de Almeida - cujo estilo se aproxima do de "Bain" de Millet - que ambos os grupos estavam longe de compartilhar das vanguardas européias do momento. No ta-se, aliás em Klaxon, excetuando-se talvez a colaboraçāo de Mário de Andrade, que o grupo, depois da Semana de Artc Moderna, procurava uma direcão vanguardista, sem estar realmente informado c integrado nela. Dai se sentirem à vontade com uma revista do nível de La Criée. E o estudo de Sérgio Milliet sobre Henri Mugnier, comprovarn que tanto Klaxon quanto La Criée, ainda estavam presos aos modismos de antes da guerra, ao néo-simbolismo, sendo que os rasgos de modernidade de ambas as revistas, não iam além das já superadas reccitas futuristas. Eis, por exemplo, um trecho do que escreve Sérgio Milliet, sobre Henri Nugnier:

16 La Criée, Marseille, (19), déc. 1922. 
Le plus souvent le poète chantc la solitude, le passé, la crainte de l'avenir, la misère de l'heure présente. Voici une des pages les plus caractéristiques de sa manière:

Jc suis chez moi; ma porte grince.

Je fais de la lumière. Alors

ma chambre m'apparaît dans le décor

de son implacable solitude.

Mon lit sourit un peu railleur.

Sans hâte je me déshabille.

Et je m'amuse à ses malheurs.

Et c'est fini, je vais dormir.

Ma jornée est passée sans un souvenir

Je peux tourner la page.

"La simplicité est ici poussée jusqu'au prosaisme de François Coppée. Tout le volume n'est pas aussi simple. Mas le fut-il que je ne le déplorerais pas. En ce temps de fantaisie effrenée, de stylisation aigue, de maniérisme et de snobisme, ces accents calmes, mélancoliques, résignés, reposent et charment". 17

\section{REFERFNCLAS BIBLIOGRAFICAS}

LA CRIEE, Marceille, $(8,9,12,13,14 ; 15,16,17,18,19), 1922$.

KLAXXN, S8o Paulo, (4): 16: (5): 13, (b): 14, (7): 16, 1922.

\section{Resumo}

A autora apresenta a revista francesa La Criée, editada cm Marselha entre 1921 e 1923, e que foi citada na revista modernista brasi. leira Klaxon. La Crlée, por sua vez, cita Klaxon, reproduz um artigo de Sérgio Milliet sobre Henri Mugnier e uma tradução de "O disco bolo", de Guilherme de Almeida.

Além de mostrar as relaçōes entre as duas revistas, a autora pretende dar subsídios para fixar-se objetivamente a divulgaçāo de Klaxon na França e para se compreender até onde chegava a participaçāo vanguardista dos colaboradores de Klaxon.

\section{Résumé}

L'auteur présente la revue La Criée, parue à Marseille entre 1921 et 1923 et mentionnće par la revuc moderniste brésilienne Klaxon. La Criée, à son tour, mentionne Klaxon et publie um article de Sergio Milliet sur Henri Nugnier et une traduction du poème " $O$ discobolo" de Guilherme de Almeida.

L'auteur établi les rapports entre les deux revues et elle se propose à informer sur les vraie limites de la divulgation de Klaxon en France et à montrer par là que les modernistes de Klaxon connaissaient mal l'avant-garde française.

17 Le Crice, Marsellle, (18): 8-9, nov, 1922. 